\title{
Serum retinol, $\beta$-carotene, and $\alpha$-tocopherol as biomarkers for disease risk and milk production in periparturient dairy cows
}

\author{
Jaimie M. Strickland, ${ }^{1}$ Lauren Wisnieski, ${ }^{2} \odot$ Thomas H. Herdt, ${ }^{1} \odot$ and Lorraine M. Sordillo ${ }^{1 *} \oplus$ \\ ${ }^{1}$ Department of Large Animal Clinical Sciences, College of Veterinary Medicine, Michigan State University, 784 Wilson Rd., East Lansing 48824 \\ ${ }^{2}$ Center for Animal and Human Health in Appalachia, College of Veterinary Medicine, Lincoln Memorial University, 6965 Cumberland Gap \\ Parkway, Harrogate, TN 37752
}

\begin{abstract}
The effectiveness of using serum vitamin concentrations as biomarkers to predict diseases in dairy cows during the periparturient period is not well known. The objective of this study was to evaluate the association between serum $\beta$-carotene, retinol, and $\alpha$-tocopherol concentrations and periparturient cow diseases in commercial dairies. We measured serum concentrations of these vitamin-active compounds at dry-off and during close-up (approximately $3 \mathrm{wk}$ before calving) and early lactation (approximately $7 \mathrm{~d}$ post-calving), and we examined their association with clinical diseases in the first $30 \mathrm{~d}$ in milk. Diseases were diagnosed by trained personnel and recorded using database software. Blood samples were taken from 353 cows from 5 different farms over a 3 -yr period. Blood samples were analyzed for $\beta$-carotene, retinol, $\alpha$-tocopherol, and cholesterol. We built separate mixed logistic regression models for each disease outcome: hyperketonuria, lameness, mastitis, uterine diseases (retained placenta or metritis), and an aggregate outcome. For the aggregate outcome, a cow was considered positive if she had one or more of the following: hyperketonuria, lameness, mastitis, uterine disease, pneumonia, milk fever, or displaced abomasum. Concentrations of all 3 fat-soluble vitamins decreased significantly in early lactation relative to the 2 prepartum sampling times. Serum retinol concentrations at close-up and early lactation were negatively associated with odds of developing postpartum hyperketonuria. At early lactation, cows with uterine disease had lower serum retinol concentrations than cows without uterine disease. Similarly, lower serum retinol concentrations were associated with greater odds of having any one disease in the aggregate outcome. Firsttest 305-d mature-equivalent milk yield was positively
\end{abstract}

Received April 10, 2020.

Accepted August 23, 2020.

*Corresponding author: sordillo@msu.edu correlated with increased serum $\alpha$-tocopherol and negatively correlated with $\beta$-carotene concentrations. This study demonstrates the potential for serum $\beta$-carotene, retinol, and $\alpha$-tocopherol to serve as biomarkers for disease risk.

Key words: vitamin A, vitamin E, $\beta$-carotene, antioxidant

\section{INTRODUCTION}

Vitamins $\mathrm{A}$ and $\mathrm{E}$ are essential nutrients in the diets of dairy cows. Deficiencies in these essential vitamins can result in a range of health aberrations, including loss of vision, cardiac muscle degeneration, and an overall increase in morbidity and mortality (Frye et al., 1991; Herdt and Stowe, 1991). Serum vitamins A and $\mathrm{E}$, together with $\beta$-carotene, are also known to contribute to important antioxidant defense mechanisms and optimal immune function (Sordillo, 2016). However, vitamin requirements for immune or antioxidant functions have been shown to be greater than those for milk production (Weiss, 1998). Increased milk production during the periparturient period can result in excessive accumulation of reactive oxygen species along with a corresponding decrease in antioxidants such as $\beta$-carotene and vitamins $\mathrm{A}$ and $\mathrm{E}$, which can cause oxidative stress (Sordillo, 2005; Abuelo et al., 2015). Indeed, oxidative stress is a major contributing factor to increased disease susceptibility in periparturient cows (Sordillo and Aitken, 2009). Quantifying oxidative stress (such as damaged lipids, proteins, or DNA) to measure disease risk is often not practical on commercial farms because of insensitive assays or assays that require prohibitively expensive equipment (Mavangira et al., 2016). Decreased serum concentrations of vitamins with antioxidant functions have been associated with increased incidence of periparturient cow diseases (LeBlanc et al., 2004; Sordillo, 2016). Thus, analyzing serum concentrations of $\beta$-carotene, and vitamins $\mathrm{A}$ and $\mathrm{E}$ as biomarkers for disease risk may be a viable and more widely accessible approach for disease man- 
agement, because they are routinely analyzed at several commercial laboratories.

Retinol and $\alpha$-tocopherol are the compounds analyzed in serum or plasma to quantify vitamin A and vitamin $\mathrm{E}$ activity in circulation, respectively; $\beta$-carotene is a provitamin and serves as a precursor to vitamin A (D'Ambrosio et al., 2011). Vitamins A and E are typically supplemented in the diet in the form of retinyl esters and $\alpha$-tocopherol ester, respectively; but parental supplementation is also utilized with commercially available injectables. $\beta$-carotene is not commonly supplemented in the diet, but it is consumed along with vitamin $\mathrm{E}$ in forages, primarily in ensiled hay. Serum concentrations of $\beta$-carotene, retinol, and $\alpha$-tocopherol can be affected by a complex array of conditions, including inflammation, stress, and liver function, in addition to variations in dietary concentrations (Mudron et al., 1997; Bertoni and Trevisi, 2013). Serum concentrations of $<3 \mu \mathrm{g} / \mathrm{mL} \beta$-carotene, $<150 \mathrm{ng} / \mathrm{mL}$ retinol, and $<2$ $\mu \mathrm{g} / \mathrm{mL} \alpha$-tocopherol are unusual in healthy cattle and generally considered evidence of deficiency (McMurray and Rice, 1982; Herdt and Stowe, 1991). Much of the literature is focused on inadequate serum vitamins associated with concurrent disease status, and less is known about what concentrations may be predictive of future disease risk. Common methods currently used on commercial dairies to monitor periparturient cow disease risk include serum concentrations of fatty acids and BHB (Ospina et al., 2010). However, these biomarkers are not always ideal, because they are measured during the close-up and early lactation periods, respectively, leaving insufficient time to intervene with management changes for the cohort sampled. Identifying serum biomarkers that can predict disease at dry-off may allow more time for farms to implement management changes to reduce disease risk (Wisnieski et al., 2019a).

The focus of the many reviews on vitamins and dairy cattle focus primarily on the effects of supplementation on health (Spears and Weiss, 2008; Abuelo et al., 2015; Sordillo, 2016). The utility of $\beta$-carotene, retinol, and $\alpha$-tocopherol as biomarkers for periparturient cow diseases has not yet been thoroughly considered. The objective of this study was to determine whether changes in serum concentrations of $\beta$-carotene, retinol, and $\alpha$-tocopherol from dry-off through to the early lactation period could be used to predict disease in peripartum cows. We hypothesized that reductions in serum vitamin concentrations from dry-off through to calving could serve as biomarkers for disease weeks before disease diagnosis. We performed a longitudinal, herdbased epidemiologic investigation of serum $\beta$-carotene, retinol, and $\alpha$-tocopherol concentrations in dairy cattle on 5 commercial farms at 3 specific time points through the nonlactating and early lactating periods.

\section{MATERIALS AND METHODS}

\section{Animals}

A total of 353 cows from 5 commercial dairy herds in Michigan were enrolled, and samples were collected over a 3 -yr period. Cohorts consisted of approximately 15 cows per cohort ( 5 nulliparous cows $<25$ mo old, 5 primiparous cows, and 5 multiparous cows). Cohorts were formed by selecting cows from the pen that were to be dried off that week, or for heifers, the equivalent length of time from their estimated calving date. At the time of dry-off, cows were approximately 200 to 230 d pregnant and $<380$ DIM. No animals in this study were kept on pasture at any point before entering the study, including animals entering their first parity. Primiparous cows may or may not have been separated from multiparous cows in the close-up or fresh pens, depending on the farm. All cows in this study were fed a TMR that consisted primarily of corn and hay silages. Commercial vitamin mixtures were provided, but the purpose of this study was not to evaluate supplementation status. All cows were bred by AI, which provided more accurate estimations of impending calving dates relative to natural breeding.

\section{Health Monitoring}

The health status of each cow was monitored from dry-off to $30 \mathrm{~d}$ post-calving and recorded using Dairy COMP305 (Valley Agricultural Software, Tulare, CA) or PCDART (Dairy Records Management Software, Ames, IA) on-farm software. On each farm, trained individuals were responsible for monitoring the health of cows daily from calving to 30 DIM. Herd veterinarians confirmed disease diagnoses when needed. Negative health outcomes of interest included milk fever, mastitis, metritis, retained placenta, lameness, displaced abomasum, hyperketonuria, and pneumonia. Case definitions for disease diagnosis followed by all farms in this study have been described previously and will be briefly defined here (Wisnieski et al., 2020). Milk fever was diagnosed by the presence of clinical signs, including muscle weakness, nervousness, muscle tremors, cold ears, and the inability to rise. Mastitis was diagnosed by the appearance of abnormal milk, such as the presence of flakes or clots visualized when milk was stripped at each milking. Cows were monitored for metritis daily, which was defined as the presence of abnormal vaginal discharge and a flaccid uterus that was found by transrectal palpation not to have involuted normally within the first 21 DIM. A cow was diagnosed with retained placenta when fetal membranes were not expelled within $24 \mathrm{~h}$ post-calving. Lameness was moni- 
tored daily and diagnosed by presence of an abnormal gait, equivalent to a score of $\geq 3$ on a scale of 1 to 5 (Sprecher et al., 1997). Only new cases of lameness that occurred during the first 30 DIM were included. Displaced abomasum was diagnosed by auscultation of the area between the 9th and 12th rib and detecting a ping when thumping the body wall. Hyperketonuria was diagnosed by the presence of urine acetoacetate concentrations $\geq 1.5 \mathrm{mmol} / \mathrm{L}$ (Ketostix; Bayer AG, Leverkusen, Germany) during daily health assessments of fresh cows 2 to $10 \mathrm{~d}$ postpartum. Pneumonia was diagnosed by the presence of abnormal lung sounds on auscultation of the thorax, altered breathing patterns, and usually with a body temperature $>39.4^{\circ} \mathrm{C}$. Cows with other negative health outcomes, such as abortion and death, were excluded from the analysis. Each farm fed a TMR supplemented with vitamin A and vitamin E. Parenteral vitamin supplementation was not used in adult cows on any of the farms included in the study. The Animal Use and Care Committee at Michigan State University (East Lansing) approved this study and all animal protocols (03/17-033-00).

\section{Vitamin Analysis}

Blood samples were collected from coccygeal vessels into blood tubes without anticoagulants. The samples were collected at dry-off ( $-48 \pm 12 \mathrm{~d}$ pre-calving), closeup $(-17 \pm 7 \mathrm{~d}$ pre-calving $)$, and early lactation $(7 \pm 3 \mathrm{~d}$ post-calving). Samples were transported from the farm in a chilled cooler and were typically processed within 2 $\mathrm{h}$ of collection. Serum was separated by centrifugation at $1,449 \times g$ for $15 \mathrm{~min}$ at $4^{\circ} \mathrm{C}$ and stored at $-20^{\circ} \mathrm{C}$ until analysis. All samples were analyzed within 6 mo of collection. Retinol, $\alpha$-tocopherol, and $\beta$-carotene have been found to be stable for at least 6 mo when stored at $-20^{\circ} \mathrm{C}$ (Comstock et al., 1993). Serum vitamin concentrations were analyzed at the Michigan State University Veterinary Diagnostic Laboratory (Lansing, MI) by using ultra-performance liquid chromatography and their routine method (Arnaud et al., 1991). Briefly, 5 -point calibration curves were constructed using stock $\beta$-carotene standard (absorbance of $1.29 \mathrm{AU}$ at $450 \mathrm{~nm}$; Sigma Aldrich, St. Louis, MO), retinol standard (absorbance of 0.5153 AU at $325 \mathrm{~nm}$; Sigma Aldrich), and $\alpha$-tocopherol solution (absorbance of $1.29 \mathrm{AU}$ at 292 $\mathrm{nm}$; Sigma Aldrich). For the internal standard, $12 \mu M$ apocarotenal (Sigma Aldrich) was added to standards and samples. Samples were analyzed chromatographically using a Waters Acquity system and Waters Empower Pro Chromatography Manager software (Waters Corporation, Milford, MA). All peaks were reviewed manually by trained laboratory employees after initial autointegration.

\section{Cholesterol Analysis}

Cholesterol was analyzed at the Michigan State University Veterinary Diagnostic Laboratory using a validated protocol. Briefly, cholesterol was analyzed using a commercially available assay (Beckman Coulter Inc., Brea, CA) by colorimetric measurement on an autoanalyzer (Olympus AU 640e; Beckman Coulter Inc.). Cholesterol was analyzed as a relative indicator of serum lipoprotein concentrations. Variation in serum lipoprotein concentrations could potentially confound the interpretation of serum $\alpha$-tocopherol concentrations (Herdt and Smith, 1996).

\section{Statistical Analysis}

Graphpad Prism version 6 (GraphPad Software, San Diego, CA) was used to create a table of mean concentrations of biomarkers (retinol, $\alpha$-tocopherol, $\beta$-carotene) for cows with each disease outcome (mastitis, uterine disease, hyperketonuria, lameness, and the aggregate outcome) or without disease in the first 30 DIM. A 2-tailed Mann-Whitney U test was used to assess statistical significance at each time point (dry-off, close-up, and early lactation). Serum vitamin concentrations are reported as mean \pm standard error of the mean.

Correlation Analyses. The pwcorr command in Stata version 14.2 (StataCorp., College Station, TX) was used to perform Pearson correlation analyses to assess the correlation between each biomarker ( $\beta$-carotene, $\alpha$-tocopherol, retinol, and cholesterol) at each sample point (dry-off, close-up, and early lactation). The normality of the biomarkers was visually assessed using quantile-quantile plots and histograms. If a biomarker violated the normality assumption, it was transformed (i.e., log-transformation) before running the Pearson correlation analysis. Scatterplots were used to verify a linear relationship between each pair of biomarkers before calculation of the Pearson correlation coefficient.

Descriptive Models. Linear mixed models were built in SAS 9.4 (SAS Institute Inc., Cary, NC) using the PROC MIXED command. A separate linear mixed model was built for each of the vitamin biomarkers ( $\beta$-carotene, retinol, and $\alpha$-tocopherol). The explanatory candidate variables for entry into the models included parity $(1,2$, or $3+)$, season, and time point. Seasons were defined as spring (March-May), summer (June-August), fall (September-November), and winter (December-February). A parity $\times$ time point interaction term was also included to investigate trends in biomarker concentrations over time in different parity groups. Backward selection was performed at an $\alpha$ of 0.05 to select the variables in the final model. Candidate 
variables that were not statistically significant were removed from the model. A random intercept for cow in the REPEATED statement was used to account for the correlation between samples that were collected from the same cow over time. A spatial covariance matrix was used to adjust for unequal spacing between time points. Random intercepts for the farm and cohort level were included to reflect the structure of the data, unless their variance estimates were negligible. A solution for random effects matrix was used to determine differences in variables between farms. Multicollinearity was carefully monitored throughout model-building by assessing if inflated standard errors and large changes in coefficients occurred after removing a variable. If multicollinearity was present, the problematic variable was removed. Heteroskedasticity of residuals across levels of the categorical variables in the final models was assessed via box plots and Levene's test. If heteroskedasticity was present, variances were estimated separately by the categorical variable, and degrees of freedom were estimated using the Satterthwaite approximation. Normality of residuals was assessed via quantile-quantile plots and histograms. Variables were transformed to meet normality assumptions if necessary. All statistical comparisons between levels of categorical variables in the models were performed using a Bonferroni adjustment for multiple comparisons.

Milk Production Model. A linear mixed model was built to assess the association between $\beta$-carotene, retinol and $\alpha$-tocopherol and milk production [reported as 305-d mature-equivalent milk yield (ME305) estimated from first milk test]. Candidate variables were parity; season; time point; cholesterol; interaction terms between each biomarker and time point; interaction terms between each biomarker and parity; and interaction terms between cholesterol and both $\alpha$-tocopherol and $\beta$-carotene. The final variables were selected using a backward selection procedure with an $\alpha$ of 0.05 . Random intercepts for cohort and farm were included using the RANDOM statement. A random intercept for cow was included in the REPEATED statement to account for repeated samples from the same cow. The default variance components covariance structure was used due to convergence issues with the spatial covariance matrix. Heteroskedasticity and normality of residuals were tested using the methods described above for the descriptive models. A Bonferroni adjustment was used to adjust for multiple comparisons for comparisons between levels of categorical variables.

Disease Models. Mixed logistic regression models were built in SAS 9.4 using the PROC GLIMMIX command with a binomial distribution. A separate logistic regression model was built for each disease outcome: hyperketonuria, lameness, mastitis, uterine diseases (retained placenta or metritis), and an aggregate outcome (hyperketonuria, lameness, mastitis, uterine diseases, pneumonia, milk fever, or displaced abomasum). The variables eligible for entry into each model included retinol, $\beta$-carotene, $\alpha$-tocopherol, parity, cholesterol, and season. Cholesterol was included as an independent variable in our disease models - alone and as an interaction term with both $\alpha$-tocopherol and $\beta$-carotene - to adjust for the influence of lipoprotein concentration on serum $\alpha$-tocopherol and $\beta$-carotene concentrations. Two-way interactions between each biomarker and time point, between each biomarker and lactation group, and between cholesterol and both $\alpha$-tocopherol and $\beta$-carotene, were included in variable selection if the number of events per variable was at least 5 (Vittinghoff and McCulloch, 2007). Multivariate modeling involved a backward selection procedure using an $\alpha$ of 0.05 . A random intercept for cow in the RANDOM statement was used to account for observations from the same cow. The default variance components covariance structure was used because of convergence issues with the spatial covariance structure. Random intercepts for the farm and cohort level were included to reflect the structure of the data, unless their variance estimates were negligible. The assumption of linearity of the association between each continuous variable and the outcome on the log odds scale was assessed via a lowess smoothing curve. Continuous variables that violated this assumption were either transformed (i.e., square root, log) or made into a categorical variable with 4 levels based on the distribution of that variable. All comparisons between categorical variables present in the models were performed using a Bonferroni adjustment for multiple comparisons. The odds ratios (OR), and corresponding standard errors and confidence intervals were calculated for each variable in the final multivariable logistic regression models.

\section{RESULTS}

\section{Study Sample}

This study included 353 cows from 28 cohorts. However, 4 cows were lost to follow-up and were excluded from the disease models. Among the 349 cows that were followed through calving, 27 had hyperketonuria (8\%), 19 had mastitis (5\%), 40 had metritis or retained placenta (11\%), and 23 had lameness $(7 \%)$. In total, 111 cows (32\%) had 1 clinical disease or more (hyperketonuria, lameness, mastitis, uterine diseases, pneumonia, milk fever, or displaced abomasum). Data from rations from all 5 farms can be found in Table 
Table 1. Formulated ration summary from farms

\begin{tabular}{llcc}
\hline Farm & Group & $\begin{array}{c}\text { Vitamin A } \\
(\mathrm{kIU} / \mathrm{kg} \text { of DM) }\end{array}$ & $\begin{array}{c}\text { Vitamin } \mathrm{E} \\
(\mathrm{IU} / \mathrm{kg} \text { of DM })\end{array}$ \\
\hline \multirow{2}{*}{2} & Far-off dry & 3.50 & 22.0 \\
& Close-up dry & 6.14 & 20.5 \\
\multirow{2}{*}{2} & Fresh cows & 1.45 & 9.2 \\
& Far-off dry & 2.80 & 20.1 \\
& Close-up dry & 5.80 & 32.4 \\
3 & Fresh cows & 0.91 & 9.9 \\
& Far-off dry & 2.52 & 8.2 \\
\multirow{4}{*}{4} & Close-up dry & 3.36 & 33.4 \\
& Fresh cows & 1.96 & 39.6 \\
& Far-off dry & 7.92 & 82.8 \\
5 & Close-up dry & 12.58 & 94.1 \\
& Fresh cows & 7.52 & 46.3 \\
& Far-off dry & 1.40 & 24.8 \\
& Close-up dry & 3.62 & 33.4 \\
& Fresh cows & 2.09 & 8.71 \\
\hline
\end{tabular}

1. Summary statistics for the biomarkers used in this study are presented in Table 2 . The correlation between each biomarker at each sample Table 3 .

\section{Descriptive Analyses}

$\beta$-Carotene. Linear mixed model results for $\beta$-carotene are shown in Table 4 . The final model included time point $(P<0.01)$, parity group $(P<0.01)$, season $(P<0.01)$, and parity $\times$ time point interaction $(P<0.01)$. Concentrations of $\beta$-carotene decreased from dry-off to close-up $[P<0.01$; least squares means $(\mathbf{L S M}) \pm \mathrm{SE}, 3.85 \pm 1.21$ to $2.68 \pm 1.21 \mu \mathrm{g} / \mathrm{mL}]$ and from close-up to early lactation $(P<0.01 ; 2.68 \pm 1.21$ to $1.22 \pm 1.21 \mu \mathrm{g} / \mathrm{mL})$. The $\beta$-carotene concentrations were greater in cows in parity 2 and $3+$ than in cows in parity $1(P<0.01 ; 2.52 \pm 1.21,2.69 \pm 1.21$, and 1.85 $\pm 1.21 \mu \mathrm{g} / \mathrm{mL}$, respectively). However, concentrations were not different between cows in parity 2 and $3+(P$ $=0.12$ ). Concentrations of $\beta$-carotene were higher in summer than in spring $(P<0.01)$ and winter $(P=$ $0.04 ; 2.69 \pm 1.22,2.2 \pm 1.22$, and $2.16 \pm 1.22 \mu \mathrm{g} / \mathrm{mL}$, respectively). The parity $\times$ time point interaction indicated that cows in parity groups 2 and $3+$ had smaller declines in $\beta$-carotene concentrations from close-up to early lactation compared with cows in parity 1 . Serum $\beta$-carotene concentrations were different between farms $(P<0.05)$.

Retinol. Linear mixed model results for retinol are presented in Table 5. The variables in the final model included time point $(P<0.01)$, parity $(P<0.01)$, and parity $\times$ time point interaction $(P=0.003)$. Retinol concentrations increased from dry-off to close-up $(P<$ $0.01 ; \mathrm{LSM} \pm \mathrm{SE}, 312.74 \pm 16.15$ to $283.68 \pm 16.20 \mathrm{ng} /$ $\mathrm{mL}$ ) and then decreased from close-up to early lactation $(P<0.01 ; 283 \pm 16.20$ to $250.50 \pm 16.26 \mathrm{ng} / \mathrm{mL})$. Retinol concentrations were significantly higher among

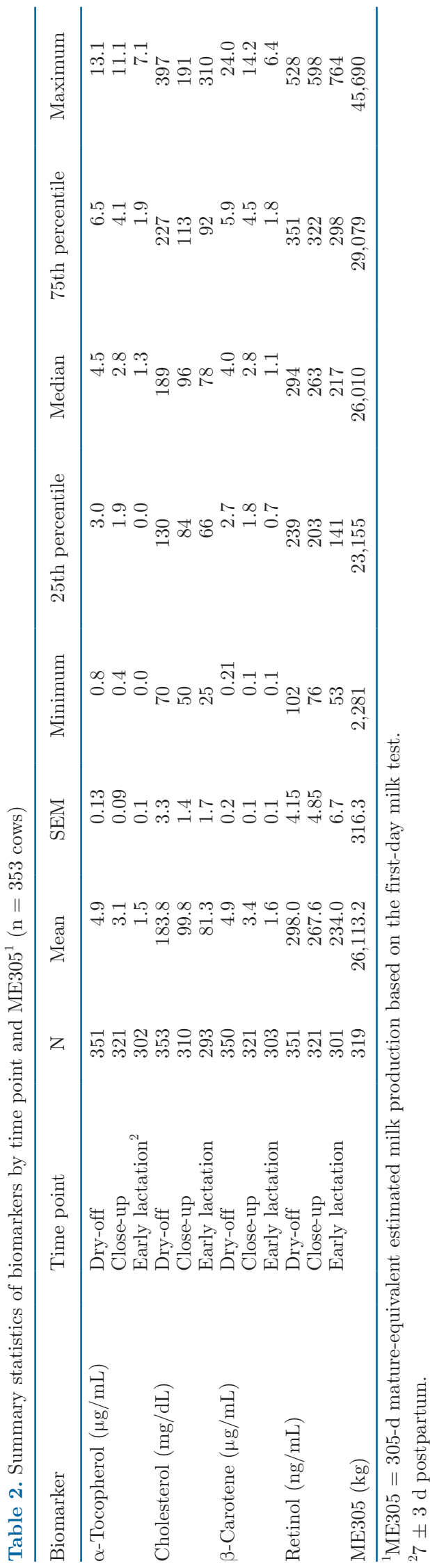


Table 3. Correlation matrix of biomarkers by sample period $(\mathrm{n}=353$ cows $)$

\begin{tabular}{|c|c|c|c|c|}
\hline Period and biomarker & $\alpha$-Tocopherol ${ }^{1}$ & Cholesterol $^{1}$ & $\beta$-Carotene ${ }^{1}$ & Retinol \\
\hline \multicolumn{5}{|l|}{ Dry-off } \\
\hline$\alpha$-Tocopherol ${ }^{1}$ & 1 & & & \\
\hline Cholesterol $^{1}$ & $0.70^{* *}$ & 1 & & \\
\hline$\beta$-Carotene ${ }^{1}$ & $0.17^{* *}$ & $0.33^{* *}$ & 1 & \\
\hline Retinol & $0.17^{* *}$ & $0.28^{* *}$ & $0.36^{* *}$ & 1 \\
\hline \multicolumn{5}{|l|}{ Close-up } \\
\hline$\alpha$-Tocopherol ${ }^{1}$ & 1 & & & \\
\hline Cholesterol $^{1}$ & $0.40^{* *}$ & 1 & & \\
\hline$\beta$-Carotene ${ }^{1}$ & $0.31^{* *}$ & 0.04 & 1 & \\
\hline Retinol & $0.35^{* *}$ & -0.06 & $0.18^{* *}$ & 1 \\
\hline \multicolumn{5}{|l|}{ Early lactation ${ }^{2}$} \\
\hline$\alpha$-Tocopherol ${ }^{1}$ & 1 & & & \\
\hline Cholesterol $^{1}$ & $0.48^{* *}$ & 1 & & \\
\hline$\beta$-Carotene ${ }^{1}$ & $0.22^{* *}$ & $0.32^{* *}$ & 1 & \\
\hline Retinol & $0.25^{* *}$ & $0.39^{* *}$ & $0.57^{* *}$ & 1 \\
\hline
\end{tabular}

${ }^{1}$ Log-transformed (base 10) to meet linearity assumptions.

${ }^{2} 7 \pm 3$ d postpartum.

$* *$ Denotes statistical significance at ${ }^{* *} \alpha=0.01$.

cows in parity 2 compared with cows in parity $3+(P<$ $0.01 ; 294 \pm 16.25$ and $269.04 \pm 16.16 \mathrm{ng} / \mathrm{mL}$, respectively). Retinol concentrations decreased from dry-off to close-up and from close-up to early lactation among cows in parity $3+$. In cows in parity 2 , serum retinol decreased from dry-off to close-up, and then increased from close-up to early lactation. Retinol concentrations remained relatively steady from dry-off to close-up and from close-up to early lactation among cows in parity 1 . Interestingly, despite wide ranges in formulated vitamin A supplementation, concentrations of serum retinol were not different between farms $(P>0.05)$.

$\alpha$-Tocopherol. Linear mixed model results for the $\alpha$-tocopherol are shown in Table 6 . The final model included time point $(P<0.01)$, parity $(P<0.01)$, and parity $\times$ time point interaction $(P<0.01)$. From dry-off to close-up, $\alpha$-tocopherol decreased $(P<0.01$; $\mathrm{LSM} \pm \mathrm{SE}, 4.69 \pm 1.09$ to $3.00 \pm 1.09 \mu \mathrm{g} / \mathrm{mL})$ and then further decreased from close-up to early lactation $(P<0.01 ; 3.00 \pm 1.09$ to $1.44 \pm 1.09 \mu \mathrm{g} / \mathrm{mL})$.

Table 4. Linear mixed model results for $\beta$-carotene $(\mathrm{n}=353 \text { cattle })^{1}$

\begin{tabular}{|c|c|c|c|c|c|c|}
\hline Variable & Coefficient & $\mathrm{SE}$ & $\mathrm{LSM}^{2}$ & SE for LSM & t-value & $P$-value \\
\hline Dry-off & Referent & & 3.85 & 1.21 & & \\
\hline Close-up & -0.16 & 0.03 & 2.68 & 1.21 & -4.59 & $<0.01$ \\
\hline Parity group & & & & & & $<0.01$ \\
\hline 1 & Referent & & 1.85 & 1.21 & & \\
\hline 2 & 0.17 & 0.03 & 2.52 & 1.21 & 5.70 & $<0.01$ \\
\hline Summer & 0.09 & 0.03 & 2.69 & 1.22 & 3.34 & $<0.01$ \\
\hline Fall & 0.01 & 0.03 & 2.27 & 1.22 & 0.41 & 0.68 \\
\hline Winter & -0.01 & 0.03 & 2.16 & 1.22 & -0.30 & 0.76 \\
\hline Time point $\times$ parity group & & & & & & $<0.01$ \\
\hline Dry-off and parity 1 & Referent & & & & & \\
\hline Close-up and parity 2 & 0.01 & 0.04 & & & 0.19 & 0.85 \\
\hline
\end{tabular}


Table 5. Linear mixed model results for retinol $(\mathrm{n}=353 \text { cattle })^{1}$

\begin{tabular}{|c|c|c|c|c|c|c|}
\hline Variable $^{2}$ & Coefficient & $\mathrm{SE}$ & LSM & SE for LSM & t-value & $P$-value \\
\hline Dry-off & Referent & & 312.74 & 16.15 & & \\
\hline Close-up & 5.62 & 9.92 & 283.68 & 16.20 & 0.57 & 0.57 \\
\hline Parity group & & & & & & $<0.01$ \\
\hline 1 & Referent & & 283.24 & 16.27 & & \\
\hline 2 & 40.50 & 9.44 & 294.63 & 16.25 & 4.29 & $<0.01$ \\
\hline Dry-off and parity 1 & Referent & & & & & \\
\hline Close-up and parity 2 & -40.30 & 13.53 & & & -2.98 & 0.003 \\
\hline Close-up and parity $3+$ & -63.73 & 12.78 & & & -4.99 & $<0.01$ \\
\hline Early lactation ${ }^{2}$ and parity 2 & -47.02 & 13.86 & & & -3.39 & $<0.01$ \\
\hline Early lactation $^{2}$ and parity $3+$ & -97.68 & 13.04 & & & -7.49 & $<0.01$ \\
\hline Intercept & 286.04 & 17.13 & & & 16.70 & $<0.01$ \\
\hline
\end{tabular}

${ }^{1}$ Adjusted for heterogeneous variances by parity. Covariance parameter estimates and 95\% CI: farm: $315.97\left(41.6-1.2 \times 10^{10}\right)$; cohort: $4,753.91$ $(2,824.3-9,642.6)$; cow (spatial power): parity $1=0.81$ ( -0.64 to 2.26$)$, parity $2=0.97(0.94-1.01)$, parity $3+=0.98(0.96-1.00)$.

${ }^{2} 7 \pm 3$ d postpartum.

Overall, $\alpha$-tocopherol was highest in cows in parity 2, followed by cows in parity $3+$, and lowest in cows in parity $1(3.03 \pm 1.09,2.72 \pm 1.09$, and $2.46 \pm 1.09 \mu \mathrm{g} /$ $\mathrm{mL}$ respectively). The parity $\times$ time point interaction indicated that $\alpha$-tocopherol concentrations were significantly lower in cows in parity 1 at dry-off compared with cows in parity 2 or $3+$, but were not significantly different from cows in parity 2 or $3+$ at close-up or early lactation. Surprisingly, serum $\alpha$-tocopherol concentrations did not differ between farms $(P>0.05)$.

Milk Production Model. The final model for firsttest ME305 is presented in Table 7. Among cows in parity 1, ME305 was lower compared with cows in parity 2 and $3+(P<0.01 ; \mathrm{LSM} \pm \mathrm{SE}, 24,162 \pm 1,029.19$, $26,481 \pm 1,026.94$, and $27,531 \pm 1,031.14$, respectively). Higher $\alpha$-tocopherol concentrations were associated with greater ME305, especially among cows in parity 1 . Lower $\beta$-carotene concentrations were associated with higher ME305, and ME305 was significantly different between farms $(P<0.05)$.

\section{Disease Models}

No vitamins were significantly associated with lameness or mastitis in the multivariable models; these results were omitted.

Hyperketonuria. The final logistic regression model for hyperketonuria is shown in Table 8 . The variables in the final model included parity $(P<0.01)$ and retinol $(P=0.03)$. Higher retinol concentrations were associated with lower odds of hyperketonuria $(\mathrm{OR}=0.997$, $95 \%$ CI $=0.994-0.9997)$. The OR can be interpreted

Table 6. Linear mixed model results for $\alpha$-tocopherol $(\mathrm{n}=353 \text { cattle })^{1}$

\begin{tabular}{|c|c|c|c|c|c|c|}
\hline Variable & Coefficient & $\mathrm{SE}$ & LSM & $\mathrm{SE}$ for $\mathrm{LSM}^{2}$ & t-value & $P$-value \\
\hline Time point & & & & & & $<0.01$ \\
\hline Dry-off & Referent & & 4.69 & 1.09 & & \\
\hline Close-up & -0.13 & 0.02 & 3.00 & 1.09 & -5.14 & $<0.01$ \\
\hline Early lactation ${ }^{3}$ & -0.4 & 0.03 & 1.44 & 1.09 & -15.62 & $<0.01$ \\
\hline Parity group & & & & & & $<0.01$ \\
\hline 1 & Referent & & 2.46 & 1.09 & & \\
\hline 2 & 0.19 & 0.02 & 3.03 & 1.09 & 7.56 & $<0.01$ \\
\hline $3+$ & 0.13 & 0.03 & 2.72 & 1.09 & 5.05 & $<0.01$ \\
\hline Time point $\times$ parity group & & & & & & $<0.01$ \\
\hline Dry-off and parity 1 & Referent & & & & & \\
\hline Close-up and parity 2 & -0.13 & 0.04 & & & -3.56 & $<0.01$ \\
\hline Close-up and parity $3+$ & -0.08 & 0.04 & & & -2.08 & 0.04 \\
\hline Early lactation ${ }^{3}$ and parity 2 & -0.16 & 0.04 & & & -4.46 & $<0.01$ \\
\hline Early lactation ${ }^{3}$ and parity $3+$ & -0.18 & 0.04 & & & -4.84 & $<0.01$ \\
\hline Intercept & 0.57 & 0.04 & & & 14.47 & $<0.01$ \\
\hline
\end{tabular}

${ }^{1}$ Covariance parameter estimates and 95\% CI: cohort: 0.03 (0.02-0.07); cow (spatial power): 0.94 (0.87-1.01).

${ }^{2} \alpha$-Tocopherol log-transformed (base 10) to meet linearity assumptions; LSM back-transformed from log scale.

${ }^{3} 7 \pm 3$ d postpartum. 
Table 7. Linear mixed model results for ME305 $(\mathrm{n}=350 \text { cattle })^{1,2}$

\begin{tabular}{|c|c|c|c|c|c|c|}
\hline Variable & Coefficient & $\mathrm{SE}$ & LSM & SE for LSM & t-value & $P$-value \\
\hline$\alpha$-Tocopherol ${ }^{3}$ & $2,369.63$ & 663.28 & & & 3.57 & $<0.01$ \\
\hline$\beta$-Carotene ${ }^{3}$ & $-1,681.83$ & 678.32 & & & -2.48 & 0.01 \\
\hline Parity group & & & & & & $<0.01$ \\
\hline 2 & $2,318.81$ & 416.23 & 26,481 & $1,026.94$ & 5.57 & $<0.01$ \\
\hline $3+$ & $3,368.72$ & 433.47 & 27,531 & $1,031.14$ & 7.77 & $<0.01$ \\
\hline Intercept & $23,880.00$ & $1,043.68$ & & & 22.88 & $<0.01$ \\
\hline
\end{tabular}

${ }^{1}$ Three cattle missing ME305 data; ME305 = 305-d mature-equivalent estimated milk production based on the first-day milk test.

${ }^{2}$ Covariance parameter estimates and 95\% CI: farm: 4,566,744 (1,535,824-50,353,619); cohort: 1,036,697 (395,580-6,730,280); cow (spatial power): 25,456,699 (23,218,240-28,036,964).

${ }^{3}$ Log-transformed (base 10) to meet linearity assumptions.

as follows: for every $100 \mathrm{ng} / \mathrm{mL}$ increase of retinol, the odds of hyperketonuria decreased by 0.3 . This was calculated by subtracting the OR from 1 and then multiplying by 100 for ease of interpretation. Cows with hyperketonuria in the first 30 DIM had mean retinol concentrations of $230.8 \pm 14.4$ and $145.9 \pm 13.3 \mathrm{ng} / \mathrm{mL}$ at close-up and early lactation, respectively, whereas cows that did not have hyperketonuria had mean retinol concentrations of $270.8 \pm 5.1(P<0.05)$ and $240.9 \pm$ $7.0 \mathrm{ng} / \mathrm{mL}(P<0.0001)$, respectively, during the same time periods. Cows in parity 2 and $3+$ had increased odds of hyperketonuria compared with cows in parity 1 $(P=0.04$ and $P<0.01$, respectively $)$.

Uterine Disorders (Retained Placenta or Metritis). The logistic regression model for uterine disorders is presented in Table 9. The final model included parity, retinol, time point, and retinol $\times$ time point interaction. Cows in parity $3+$ had higher odds of uterine disorders cows in parity $2(P=0.03)$. The interaction term indicated that higher serum retinol concentrations at early lactation were associated with reduced odds of uterine disorders. Cows with a uterine disorder had a mean serum retinol concentration of $154.3 \mathrm{ng} / \mathrm{mL}$ at early lactation, whereas cows that did not have a uterine disorder had mean retinol concentrations of 243.4 $\mathrm{ng} / \mathrm{mL}$ at early lactation $(P<0.0001)$.

Aggregate Outcome. Variables remaining in the logistic regression model for the aggregate odds of dis- ease are presented in Table 10 and included $\beta$-carotene, retinol, $\alpha$-tocopherol, parity, $\beta$-carotene $\times$ parity interaction, and $\alpha$-tocopherol $\times$ parity interaction. Higher serum retinol concentrations were associated with a decreased odds of disease $(P<0.01)$. Cows in parity $3+$ had increased odds of disease compared to cows in parity 1 or $2(P<0.01$ and $P<0.01$, respectively $)$. Higher $\beta$-carotene concentrations were positively associated with the aggregate disease odds in cows in parity 1 but were not significantly associated with aggregate disease odds in cows in parity 2 and $3+$. Higher $\alpha$-tocopherol concentrations were associated with decreased odds of disease among cows in parity 1 , but were associated with an increased odds of disease among cows in parity 2 .

\section{DISCUSSION}

Serum concentrations of fat-soluble vitamins can be used to monitor dietary supplementation, but they are not as reliable an indicator of vitamin dietary supplementation status in dairy cattle as hepatic vitamin concentrations, because of the various factors that affect serum concentrations that are independent of storage concentrations (Van Saun et al., 1989; Herdt and Stowe, 1991). Serum retinol concentrations are particularly subject to homeostatic regulations and do not tend to deviate from the expected range in serum

Table 8. Logistic regression model for hyperketonuria $(\mathrm{n}=349 \text { cattle })^{1,2}$

\begin{tabular}{|c|c|c|c|c|c|c|}
\hline Variable & $\begin{array}{l}\text { Odds ratio } \\
\text { (OR) }\end{array}$ & SE for OR & $\begin{array}{l}\text { Lower } 95 \% \\
\text { CI for OR }\end{array}$ & $\begin{array}{l}\text { Upper } 95 \% \\
\text { CI for OR }\end{array}$ & t-value & $P$-value \\
\hline Retinol & 0.997 & 1.00 & 0.994 & 0.999 & -2.20 & 0.01 \\
\hline 2 & 1.71 & 1.29 & 1.01 & 2.82 & 2.47 & 0.01 \\
\hline $3+$ & 3.07 & 1.27 & 1.91 & 4.93 & 4.82 & $<0.01$ \\
\hline Intercept & 0.03 & 2.05 & 0.01 & 0.25 & -4.92 & $<0.01$ \\
\hline
\end{tabular}

${ }^{1}$ Four cattle excluded due to missing data.

${ }^{2}$ Covariance parameter estimates and 95\% CI: farm: 0.88 (0.15-9,873.82), cohort: 3.18 (1.63-8.72): cow (variance components): 0.49 (0.45-0.54). 
Table 9. Logistic regression model for uterine disorders $(\mathrm{n}=349 \text { cattle })^{1,2}$

\begin{tabular}{|c|c|c|c|c|c|c|}
\hline Variable & $\begin{array}{l}\text { Odds ratio } \\
\text { (OR) }\end{array}$ & $\mathrm{SE}$ for $\mathrm{OR}$ & $\begin{array}{l}\text { Lower } 95 \% \\
\text { CI for OR }\end{array}$ & $\begin{array}{l}\text { Upper } 95 \% \\
\text { CI for OR }\end{array}$ & $\mathrm{t}$-value & $P$-value \\
\hline Parity group & & & & & & 0.03 \\
\hline 1 & Referent & & & & & \\
\hline $3+$ & 1.33 & 1.27 & 0.83 & 2.13 & 1.20 & 0.23 \\
\hline Time point & & & & & & 0.15 \\
\hline Dry-off & Referent & & & & & \\
\hline Retinol $\times$ time point & & & & & & 0.04 \\
\hline Dry-off & Referent & & & & & \\
\hline Close-up & 0.998 & 1.00 & 0.99 & 1.00 & -0.47 & 0.64 \\
\hline Early lactation $^{3}$ & 0.991 & 1.00 & 0.98 & 0.998 & -2.49 & 0.01 \\
\hline Intercept & 0.26 & 2.03 & 0.04 & 1.88 & -1.89 & 0.13 \\
\hline
\end{tabular}

${ }^{1}$ Four cattle excluded due to missing data.

${ }^{2}$ Covariance parameter estimates and 95\% CI: farm: $0.02\left(0.002-2.53 \times 10^{43}\right)$; cohort: $0.32(0.14-3.14)$, cow (variance components): $0.89(0.81-$ $0.98)$.

${ }^{3} 7 \pm 3$ d postpartum.

until hepatic reserves fall below $20 \mu \mathrm{g} / \mathrm{g}$ (Kohlmeier and Burroughs, 1970). Thus, using serum vitamin concentrations as biomarkers for disease risk during the periparturient period, in addition to monitoring dietary supplementation, may prove to be an efficacious tool for improving animal health.

In the current study, decreased serum retinol was associated with increased odds for periparturient diseases. In accordance with previous studies, most cows, with the exception of those in parity 1 , had decreased serum retinol concentrations in the peripartum period; indeed, $28 \%$ of the cows became deficient in circulating concentrations of retinol $(<150 \mathrm{ng} / \mathrm{mL})$ at early lactation (Herdt and Stowe, 1991; Goff et al., 2002). Furthermore, cows that were diagnosed with uterine disease had a mean serum retinol concentration that was $100 \mathrm{ng} / \mathrm{mL}$ lower than their herd mates without metritis or retained placenta at early lactation. These findings could suggest that decreased serum retinol heightens the odds of retained placenta and metritis due to the substantial role of vitamin A in multiple facets of immunity (Duriancik et al., 2010; Sirisinha, 2015; Larange and Cheroutre, 2016). However, the low serum retinol concentrations in the periparturient period were transient and may have been the effect, rather than the cause, of metritis and its associated inflammation. Serum retinol concentrations are dependent on the presence of retinol-binding protein (RBP), a short-half-life protein produced by hepatocytes and adipocytes (Contreras et al., 2017). Synthesis and

Table 10. Logistic regression model for aggregate outcome $(\mathrm{n}=349 \text { cattle })^{1,2}$

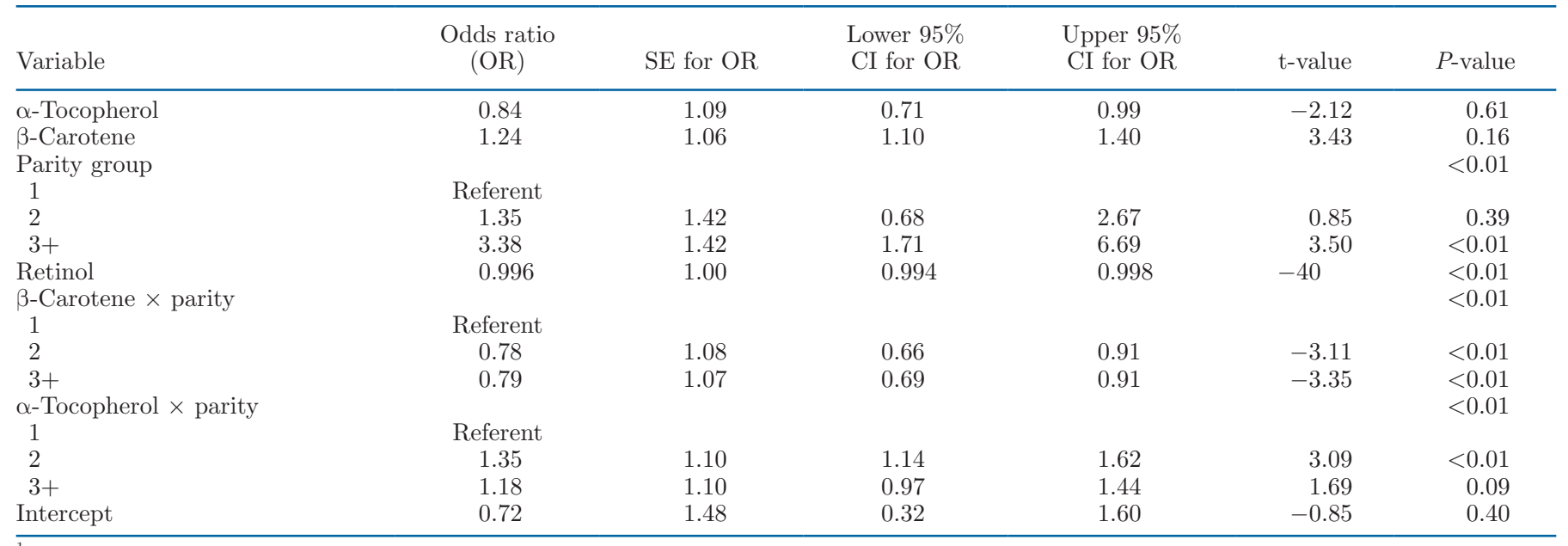

${ }^{1}$ Four cattle excluded due to missing data.

${ }^{2}$ Covariance parameter estimates and 95\% CI: cohort: 0.59 (0.32-1.48), cow (variance components): 0.95 (0.87-1.04). 
secretion of RBP is necessary for the mobilization of retinol from hepatic stores, and $\mathrm{RBP}$ is a "negative acute phase" protein (Smith et al., 1973a; Bertoni et al., 2008), indicating that its synthesis and secretion are suppressed by generalized inflammation. Through this mechanism, serum retinol concentrations might be depressed by inflammation resulting from metritis.

Hyperketonuria was significantly associated with decreased serum retinol concentrations at both close-up and early lactation. Hyperketonuria results from hyperketonemia, which is a well-established risk factor for early culling, periparturient morbidity, and decreased reproductive performance (LeBlanc, 2010; Probo et al., 2018). Hyperketonemia results from negative energy balance, rapid adipose mobilization, and high glucose demand. In association with these metabolic conditions, cows in the first 2 wk of lactation are, on average, in substantial negative protein balance, which is created by the amino acid demands for gluconeogenesis as well as for milk production (Bell, 1995). This demand for amino acids could limit the synthesis of RBP, resulting in low serum retinol concentrations at early lactation (Smith et al., 1973a,b; Shenkin et al., 1996). However, this does not explain the decrease in serum retinol prepartum. Retinol has been shown to decrease in response to fasting independent of RBP, as well as in response to LPS treatment (Abd Eldaim et al., 2010). Therefore, decreased retinol at close-up in cows that later developed hyperketonuria may have reflected decreased feed intake or some inflammatory process. The association between serum retinol and disease conditions as observed in this study may result from a complex interplay of nutrition, metabolism, and inflammation.

Changes in serum retinol concentration between time points varied significantly between parity 1 and parity 2 or greater. These results differed from previous reports on serum retinol concentrations during the periparturient period in that not all cows, specifically cows in parity 1 , experience a decrease in serum retinol concentrations (Johnston and Chew, 1984; Goff et al., 2002; LeBlanc et al., 2004). It was clear, however, that cows in parity $3+$ had greater odds of low serum retinol concentrations than cows in parity 1 or 2 . Although colostrum has been shown to be a large contributor to the decrease in serum retinol concentrations postpartum, cows in parity 1 have been shown to have higher concentrations of retinol in their colostrum than multiparous cows (Kume, 1993; Goff et al., 2002). Because vitamin A concentrations in colostrum were not analyzed in this study, its contributions to decreased serum retinol concentrations are unknown.

The reduction we observed in serum $\alpha$-tocopherol from dry-off to close-up and from close-up to early lactation was observed in previous studies (Herdt and
Smith, 1996; Goff et al., 2002). In the aggregate disease model, greater serum $\alpha$-tocopherol concentrations were associated with decreased disease odds in cows in parity 1 , but not in cows in parity 2 . The mechanism behind this finding is unknown, but may be associated with the increased stress cows parity 1 experience in the peripartum period. Alternatively, excess circulating $\alpha$-tocopherol may be detrimental to the health of cows and may have contributed to the association between increased serum $\alpha$-tocopherol and greater disease odds for cows in parity 2 in this study. Bouwstra et al. (2008) demonstrated that cows in parity 1 with mean serum $\alpha$-tocopherol concentrations of approximately $3.8 \mu \mathrm{g} /$ $\mathrm{mL}$ at calving had increased markers of oxidative stress than cows with $\alpha$-tocopherol concentrations of $1.9 \mu \mathrm{g} /$ $\mathrm{mL}$. This same group later proposed that $\alpha$-tocopherolinduced oxidative stress increased risk of diseases such as mastitis (Bouwstra et al., 2010). In the current study, cows in parity 1 and 2 averaged 3.0 and $3.6 \mu \mathrm{g} /$ $\mathrm{mL} \alpha$-tocopherol over the study period, respectively.

Serum lipoproteins constitute the major pool of neutral lipids in serum, and this pool size varies markedly over the peripartum period in cattle. Most of the $\alpha$-tocopherol and $\beta$-carotene molecules in serum are distributed into this pool (Herdt and Smith, 1996). Cholesterol constitutes a major and consistent portion of the serum lipoprotein pool, and thus its serum concentration can serve as a relative indicator of this pool size. To examine the potential influence of variation in serum lipoprotein pool size on the interpretation of serum $\alpha$-tocopherol and $\beta$-carotene concentrations, we included cholesterol as an independent variable in our analyses. We observed no interaction between $\alpha$-tocopherol or $\beta$-carotene and cholesterol with respect to prediction of disease, and we concluded that adjustment for serum neutral lipid pool size did not enhance the biomarker function of these compounds. One intriguing result was that, despite great variation in formulated supplementation rates, serum $\alpha$-tocopherol rates did not differ between farms. This could have been due to uniformly decreased circulating lipoproteins, decreased feed intake, variation in vitamin $\mathrm{E}$ content of the basal diet, differences in dietary polyunsaturated fatty acids, or variation in the storage, quality, or handling of supplements on each farm (NRC, 2001; Arfuso et al., 2016).

Serum concentrations of $\beta$-carotene decreased from dry-off to close-up and from close-up to early lactation and were greater in cows in parity 2 and $3+$ compared with cows in parity 1 . This trend was similar to that observed previously in periparturient cows (Goff et al., 2002; Rosendo et al., 2010). Higher serum $\beta$-carotene concentrations were associated with decreased milk production. Serum $\beta$-carotene concentrations may 
be decreased in higher-producing cows because of its increased consumption as a free-radical scavenger. High-producing cows would generate more free radicals through a greater need for energy production than lower-producing cows and thus may use an increased amount of serum antioxidants such as $\beta$-carotene (Sordillo, 2016). Alternatively, both serum $\beta$-carotene concentrations and ME305 were significantly different between farms, and it is possible that farms with lower ME305 were feeding more $\beta$-carotene-containing ingredients such as forages in their diets, as opposed to concentrates. The ME305 is a convenient tool for monitoring milk production during the transition period because it adjusts for varying DIM on test-day, lactation number, season, age, and area of the country (Nordlund and Cook, 2004; Cook et al., 2006). Additionally, ME305 calculated from first-test data is a reliable indicator of milk yield, disease, and fertility (Heuer et al., 1999). First test-day milk, even if adjusted for days since parturition, could be affected by other factors such as season, and our study was conducted throughout an entire year. Although use of 1 early lactation test-day milk yield to calculate 305-d milk production can underestimate milk yield, ME305 from the first test day is an early and unbiased method for monitoring performance in early lactation (Nordlund and Cook, 2004; López et al., 2015).

The present observational study was a broad investigation of the association between serum concentrations of $\beta$-carotene, retinol, and $\alpha$-tocopherol with animal health. As such, we could not make broad conclusions about the potential mechanisms involved in the link between serum vitamins and disease. In the case of uterine disease, for example, blood samples were collected at $7 \pm 3$ DIM, and metritis and retained placenta were diagnosed at $5.5 \pm 3.6$ and $1.1 \pm 1$ DIM, respectively. Therefore, in this case, serum retinol concentrations reflected the circulating retinol status at approximately the time of disease occurrence. Cows with hyperketonuria, however, had significantly lower serum retinol at the time of their move to a close-up pen. The close-up sample was taken an average of $24 \pm 10 \mathrm{~d}$ before a diagnosis of hyperketonuria, and thus a temporal association was present in this case (data not shown). Indeed, the relationship between the time of sample collection and disease occurrence in this study could have biased our results to capture only associations between serum vitamins and diseases that occur immediately after calving. For example, lameness and mastitis may have been diagnosed 2 to $3 \mathrm{wk}$ after sample collection, and therefore our analyzed sample did not accurately represent vitamin metabolism at the time of disease. Although lameness has not traditionally been considered a fresh cow disease, the risk for developing lameness has been found to increase significantly following a decrease in BCS, which occurs frequently postpartum (Randall et al., 2015).

The current study took place on 5 different commercial dairy farms with variations in both management practices and formulated supplementation rates of vitamins $\mathrm{A}$ and $\mathrm{E}$. The objective of this study was to assess the association between serum concentrations of $\beta$-carotene, retinol, and $\alpha$-tocopherol on disease risk in the periparturient period. Farms differed in practices such as providing separate close-up and fresh pens for primiparous and multiparous cows. Although different management practices can certainly affect the incidence of fresh cow diseases, collecting data from multiple commercial farms strengthens the translatability of these results to practical on-farm use in the future. Furthermore, all farms had excellent management practices, as illustrated by their low incidence of disease during the fresh period. For example, the incidence of metritis and retained placenta over $1 \mathrm{yr}$ in the current study was 7.22 and $6.5 \%$, respectively (Wisnieski et al., 2019b). Another similar study conducted on large commercial farms found that metritis had a mean incidence of $17.1 \%$ and retained placenta had an incidence of $12.3 \%$ (Vergara et al., 2014).

\section{CONCLUSIONS}

The findings of the current study demonstrate that certain serum vitamin concentrations could serve as biomarkers for some diseases when analyzed at strategic points during the lactation cycle. Serum vitamin concentrations have been used to determine the supplementation status of a herd, but in the case of well managed herds such as those in the current study, they might also serve as biomarkers for much more complex processes such as inflammation and hepatic function. Future studies should further investigate the association of serum concentrations of $\beta$-carotene, retinol, and $\alpha$-tocopherol with periparturient cow diseases to establish serum ranges at which these biomarkers indicate increased disease risk.

\section{ACKNOWLEDGMENTS}

The authors thank Jeff Gandy, Jennifer Brown, Ashley Putman, and Matthew Kuhn (College of Veterinary Medicine, Large Animal Clinical Sciences, Michigan State University) for their contributions in collecting and analyzing the data for this study. It would not have been possible without their help. Additionally, the authors thank the Michigan State University Veterinary Diagnostic Laboratory for so generously analyzing the serum vitamin and cholesterol concentrations. 
This study was supported, in part, by support from the Agriculture and Food Research Initiative Competitive Grants Program (2017-67015-26676) from the USDA National Institute of Food and Agriculture (Washington, DC), an endowment from the Matilda R. Wilson Fund (Detroit, MI), and the Michigan Alliance for Animal Agriculture. The authors have no conflicts of interest.

\section{REFERENCES}

Abuelo, A., J. Hernandez, J. L. Benedito, and C. Castillo. 2015. The importance of the oxidative status of dairy cattle in the periparturient period: revisiting antioxidant supplementation. J. Anim. Physiol. Anim. Nutr. (Berl.) 99:1003-1016. https://doi.org/10 $.1111 /$ jpn.12273.

Arfuso, F., F. Fazio, M. Levanti, M. Rizzo, S. Di Pietro, E. Giudice, and G. Piccione. 2016. Lipid and lipoprotein profile changes in dairy cows in response to late pregnancy and the early postpartum period. Arch. Tierzucht 59:429-434. https://doi.org/10.5194/aab $-59-429-2016$.

Arnaud, J., I. Fortis, S. Blachier, D. Kia, and A. Favier. 1991. Simultaneous determination of retinol, alpha-tocopherol and betacarotene in serum by isocratic high-performance liquid chromatography. J. Chromatogr. 572:103-116. https://doi.org/10.1016/0378 $-4347(91) 80476-\mathrm{S}$.

Bell, A. W. 1995. Regulation of organic nutrient metabolism during transition from late pregnancy to early lactation. J. Anim. Sci. 73:2804-2819. https://doi.org/10.2527/1995.7392804x.

Bertoni, G., and E. Trevisi. 2013. Use of the liver activity index and other metabolic variables in the assessment of metabolic health in dairy herds. Vet. Clin. North Am. Food Anim. Pract. 29:413-431. https://doi.org/10.1016/j.cvfa.2013.04.004.

Bertoni, G., E. Trevisi, X. Han, and M. Bionaz. 2008. Effects of inflammatory conditions on liver activity in puerperium period and consequences for performance in dairy cows. J. Dairy Sci. 91:33003310. https://doi.org/10.3168/jds.2008-0995.

Bouwstra, R. J., R. M. A. Goselink, P. Dobbelaar, M. Nielen, J. R. Newbold, and T. van Werven. 2008. The relationship between oxidative damage and vitamin E concentration in blood, milk, and liver tissue from vitamin E supplemented and nonsupplemented periparturient heifers. J. Dairy Sci. 91:977-987.

Bouwstra, R. J., M. Nielen, J. R. Newbold, E. H. J. M. Jansen, H. F. Jelinek, and T. van Werven. 2010. Vitamin E supplementation during the dry period in dairy cattle. Part II: Oxidative stress following vitamin E supplementation may increase clinical mastitis incidence postpartum. J. Dairy Sci. 93:5696-5706.

Comstock, G. W., A. J. Alberg, and K. J. Helzlsouer. 1993. Reported effects of long-term freezer storage on concentrations of retinol, beta-carotene, and alpha-tocopherol in serum or plasma summarized. Clin. Chem. 39:1075-1078. https://doi.org/10.1093/clinchem/39.6 .1075 .

Contreras, G. A., C. Strieder-Barboza, and W. Raphael. 2017. Adipose tissue lipolysis and remodeling during the transition period of dairy cows. J. Anim. Sci. Biotechnol. 8:41. https://doi.org/10 .1186/s40104-017-0174-4.

Cook, N., G. Oetzel, and K. Nordlund. 2006. Modern techniques for monitoring high-producing dairy cows 1 . Principles of herd-level diagnoses. In Pract. 28:510-515. https://doi.org/10.1136/inpract .28.9.510

D'Ambrosio, D. N., R. D. Clugston, and W. S. Blaner. 2011. Vitamin A metabolism: an update. Nutrients 3:63-103. https://doi.org/10 $.3390 /$ nu3010063.

Duriancik, D. M., D. E. Lackey, and K. A. Hoag. 2010. Vitamin A as a regulator of antigen presenting cells. J. Nutr. 140:1395-1399. https://doi.org/10.3945/jn.110.124461.
Abd Eldaim, M. A., A. Kamikawa, M. M. Soliman, M. M. Ahmed, Y. Okamatsu-Ogura, A. Terao, T. Miyamoto, and K. Kimura. 2010. Retinol binding protein 4 in dairy cows: its presence in colostrum and alteration in plasma during fasting, inflammation, and the peripartum period. J. Dairy Res. 77:27-32. https://doi.org/10.1017/ S0022029909990276.

Frye, T. M., S. N. Williams, and T. W. Graham. 1991. Vitamin deficiencies in cattle. Vet. Clin. North Am. Food Anim. Pract. 7:217275. https://doi.org/10.1016/S0749-0720(15)30817-3.

Goff, J. P., K. Kimura, and R. L. Horst. 2002. Effect of mastectomy on milk fever, energy, and vitamins A, E, and beta-carotene status at parturition. J. Dairy Sci. 85:1427-1436. https://doi.org/10.3168/ jds.S0022-0302(02)74210-0.

Herdt, T. H., and J. C. Smith. 1996. Blood-lipid and lactation-stage factors affecting serum vitamin $\mathrm{E}$ concentrations and vitamin $\mathrm{E}$ cholesterol ratios in dairy cattle. J. Vet Diagn. Invest. 8:228-232.

Herdt, T. H., and H. D. Stowe. 1991. Fat-soluble vitamin nutrition for dairy cattle. Vet. Clin. North Am. Food Anim. Pract. 7:391-415. https://doi.org/10.1016/S0749-0720(15)30796-9.

Heuer, C., Y. Schukken, and P. Dobbelaar. 1999. Postpartum body condition score and results from the first test day milk as predictors of disease, fertility, yield, and culling in commercial dairy herds. J. Dairy Sci. 82:295-304. https://doi.org/10.3168/jds.S0022 -0302(99)75236-7.

Johnston, L. A., and B. P. Chew. 1984. Peripartum changes of plasma and milk vitamin $\mathrm{A}$ and beta-carotene among dairy cows with or without mastitis. J. Dairy Sci. 67:1832-1840. https://doi.org/10 .3168/jds.S0022-0302(84)81511-8.

Kohlmeier, R. H., and W. Burroughs. 1970. Estimation of critical plasma and liver vitamin A levels in feedlot cattle with observations upon influences of body stores and daily dietary requirements. J. Anim. Sci. 30:1012-1018. https://doi.org/10.2527/jas1970 $.3061012 \mathrm{x}$.

Kume, S. 1993. Effect of parity of Holstein cows on vitamin A and $\beta$-carotene concentrations of colostrum and calf serum. Anim. Sci. Technol. (Jpn.) 64:987-991.

Larange, A., and H. Cheroutre. 2016. Retinoic acid and retinoic acid receptors as pleiotropic modulators of the immune system. Annu. Rev. Immunol. 34:369-394. https://doi.org/10.1146/annurev -immunol-041015-055427.

LeBlanc, S. 2010. Monitoring metabolic health of dairy cattle in the transition period. J. Reprod. Devel. 56(Suppl.):S29-S35.

LeBlanc, S. J., T. H. Herdt, W. M. Seymour, T. F. Duffield, and K. E. Leslie. 2004. Peripartum serum vitamin E, retinol, and beta-carotene in dairy cattle and their associations with disease. J. Dairy Sci. 87:609-619. https://doi.org/10.3168/jds.S0022-0302(04)73203 -8 .

López, S., J. France, N. E. Odongo, R. A. McBride, E. Kebreab, O. AlZahal, B. W. McBride, and J. Dijkstra. 2015. On the analysis of Canadian Holstein dairy cow lactation curves using standard growth functions. J. Dairy Sci. 98:2701-2712. https://doi.org/10 $.3168 /$ jds.2014-8132.

Mavangira, V., M. J. Mangual, J. C. Gandy, and L. M. Sordillo. 2016. 15-F-2t-Isoprostane concentrations and oxidant status in lactating dairy cattle with acute coliform mastitis. J. Vet. Intern. Med. 30:339-347. https://doi.org/10.1111/jvim.13793.

McMurray, C. H., and D. A. Rice. 1982. Vitamin E and selenium deficiency diseases. Ir. Vet. J. 36:57-67

Mudron, P., J. Rehage, H. P. Sallmann, M. Mertens, H. Scholz, and G. Kovac. 1997. Plasma and liver $\alpha$-tocopherol in dairy cows with left abomasal displacement and fatty liver. Zentralbl. Veterinarmed. A. 44:91-97.

Nordlund, K. V., and N. B. Cook. 2004. Using herd records to monitor transition cow survival, productivity, and health. Vet. Clin North Am. Food Anim. Pract. 20:627-649. https://doi.org/10.1016/j .cvfa.2004.06.012.

National Research Council. 2001. Nutrient Requirements of Dairy Cattle. 7th rev. ed. Natl. Acad. Press, Washington, DC.

Ospina, P. A., D. V. Nydam, T. Stokol, and T. R. Overton. 2010. Association between the proportion of sampled transition cows with 
increased nonesterified fatty acids and $\beta$-hydroxybutyrate and disease incidence, pregnancy rate, and milk production at the herd level. J. Dairy Sci. 93:3595-3601. https://doi.org/10.3168/jds.2010 -3074 .

Probo, M., O. B. Pascottini, S. LeBlanc, G. Opsomer, and M. Hostens. 2018. Association between metabolic diseases and the culling risk of high-yielding dairy cows in a transition management facility using survival and decision tree analysis. J. Dairy Sci. 101:94199429. https://doi.org/10.3168/jds.2018-14422.

Randall, L. V., M. J. Green, M. G. G. Chagunda, C. Mason, S. C. Archer, L. E. Green, and J. N. Huxley. 2015. Low body condition predisposes cattle to lameness: an 8-year study of one dairy herd. J. Dairy Sci. 98:3766-3777. https://doi.org/10.3168/jds.2014-8863.

Rosendo, O., L. R. McDowell, C. Staples, J. K. Shearer, N. S. Wilkinson, and W. M. Seymour. 2010. Relationship of mild fatty liver, beta-carotene, vitamins $\mathrm{A}$ and $\mathrm{E}$ status of periparturient Holstein cows. Rev. Cient. 20:399-408.

Shenkin, A., G. Cederblad, M. Elia, and B. Isaksson. 1996. Laboratory assessment of protein energy status. J. Int. Fed. Clin. Chem. 8:58-61.

Sirisinha, S. 2015. The pleiotropic role of vitamin A in regulating mucosal immunity. Asian Pac. J. Allergy Immunol. 33:71-89.

Smith, F. R., D. S. Goodman, G. Arroyave, and F. Viteri. 1973a. Serum vitamin A, retinol-binding protein, and prealbumin concentrations in protein-calorie malnutrition. II. Treatment including supplemental vitamin A. Am. J. Clin. Nutr. 26:982-987. https:// doi.org/10.1093/ajcn/26.9.982.

Smith, F. R., D. S. Goodman, M. S. Zaklama, M. K. Gabr, S. elMaraghy, and V. N. Patwardhan. 1973b. Serum vitamin A, retinolbinding protein, and prealbumin concentrations in protein-calorie malnutrition. I. A functional defect in hepatic retinol release. Am. J. Clin. Nutr. 26:973-981. https://doi.org/10.1093/ajcn/26.9.973.

Sordillo, L. M. 2005. Factors affecting mammary gland immunity and mastitis susceptibility. Livest. Prod. Sci. 98:89-99. https://doi .org/10.1016/j.livprodsci.2005.10.017.

Sordillo, L. M. 2016. Nutritional strategies to optimize dairy cattle immunity. J. Dairy Sci. 99:4967-4982. https://doi.org/10.3168/jds .2015-10354.

Sordillo, L. M., and S. L. Aitken. 2009. Impact of oxidative stress on the health and immune function of dairy cattle. Vet. Immunol. Immunopathol. 128:104-109. https://doi.org/10.1016/j.vetimm.2008 .10 .305 .
Spears, J. W., and W. P. Weiss. 2008. Role of antioxidants and trace elements in health and immunity of transition dairy cows. Vet. J. 176:70-76. https://doi.org/10.1016/j.tvjl.2007.12.015.

Sprecher, D. J., D. E. Hostetler, and J. B. Kaneene. 1997. A lameness scoring system that uses posture and gait to predict dairy cattle reproductive performance. Theriogenology 47:1179-1187. https:// doi.org/10.1016/S0093-691X(97)00098-8.

Van Saun, R. J., T. H. Herdt, and H. D. Stowe. 1989. Maternal and fetal vitamin E concentrations and selenium-vitamin E interrelationships in dairy cattle. J. Nutr. 119:1156-1164. https://doi.org/ $10.1093 /$ jn/119.8.1156.

Vergara, C. F., D. Dopfer, N. B. Cook, K. V. Nordlund, J. A. McArt, D. V. Nydam, and G. R. Oetzel. 2014. Risk factors for postpartum problems in dairy cows: explanatory and predictive modeling. J. Dairy Sci. 97:4127-4140. https://doi.org/10.3168/jds.2012-6440.

Vittinghoff, E., and C. E. McCulloch. 2007. Relaxing the rule of ten events per variable in logistic and Cox regression. Am. J. Epidemiol. 165:710-718. https://doi.org/10.1093/aje/kwk052.

Weiss, W. P. 1998. Requirements of fat-soluble vitamins for dairy cows: a review. J. Dairy Sci. 81:2493-2501. https://doi.org/10 .3168/jds.S0022-0302(98)70141-9.

Wisnieski, L., J. Brown, S. Holcombe, J. Gandy, and L. M. Sordillo. 2020. Serum vitamin D concentrations at dry-off and close-up predict increased postpartum urine ketone concentrations in dairy cattle. J. Dairy Sci. 103:1795-1806. https://doi.org/10.3168/jds .2019-16599.

Wisnieski, L., B. Norby, S. Pierce, T. Becker, J. Gandy, and L. M. Sordillo. 2019a. Cohort-level disease prediction using aggregate biomarker data measured at dry-off in transition dairy cattle: A proof-of-concept study. Prev. Vet. Med. 169:104701. https://doi .org/10.1016/j.prevetmed.2019.104701.

Wisnieski, L., B. Norby, S. Pierce, T. Becker, J. Gandy, and L. M. Sordillo. 2019b. Predictive models for early lactation diseases in transition dairy cattle at dry-off. Prev. Vet. Med. 163:68-78. https: //doi.org/10.1016/j.prevetmed.2018.12.014.

\section{ORCIDS}

Lauren Wisnieski (® https://orcid.org/0000-0003-2915-2529

Thomas H. Herdt ๑ https://orcid.org/0000-0002-2843-3217

Lorraine M. Sordillo @ https://orcid.org/0000-0001-8873-3134 